Trauma Surgery \& Acute Care Open

\title{
Diaphragm pacing decreases hospital charges for patients with acute cervical spinal cord injury
}

\author{
Andrew J Kerwin (1) , Yohan Diaz Zuniga, Brian K Yorkgitis, Jennifer Mull, Albert T Hsu, \\ Firas G Madbak, David J Ebler, David J Skarupa, Joseph Shiber, Marie L Crandall
}

Surgery, University of Florida College of Medicine Jacksonville, Jacksonville, Florida, USA

Correspondence to Dr Andrew J Kerwin; andy. kerwin@jax.ufl.edu

This study was presented at the 50th Annual Meeting of the Western Trauma Association Sun Valley, ID, February 25, 2020.

Received 27 June 2020 Revised 2 September 2020 Accepted 4 October 2020

(c) Author(s) (or their employer(s)) 2020. Re-use permitted under CC BY-NC. No commercial re-use. See rights and permissions. Published by BMJ.

\section{To cite: Kerwin AJ} Diaz Zuniga Y, Yorkgitis BK, et al. Trauma Surg Acute Care Open 2020;5:e000528.

\section{ABSTRACT \\ Background Cervical spinal cord injury (CSCI) is devastating and costly. Previous research has demonstrated that diaphragm pacing (DPS) is safe and improves respiratory mechanics. This may decrease hospital stays, vent days, and costs. We hypothesized DPS implantation would facilitate liberation from ventilation and would impact hospital charges.}

Methods We performed a retrospective review of patients with acute CSCl between January 2005 and May 2017. Routine demographics were collected. Patients underwent propensity matching based on age, injury severity score, ventilator days, hospital length of stay, and need for tracheostomy. We then adjusted total hospital charges by year using US Bureau of Labor Statistics annual adjusted Medical Care Prices. Bivariate and multivariate linear regression statistics were performed using STATA V.15.

Results Between July 2011 and May 2017, all patients with acute CSCI were evaluated for DPS implantation. 40 patients who had laparoscopic DPS implantation (DPS) were matched to 61 who did not (NO DPS). Following DPS implantation, there was a statistically significant increase in spontaneous Vt compared with NO DPS $(+88$ $\mathrm{mL} v \mathrm{vs}-13 \mathrm{~mL} ; 95 \% \mathrm{Cl} 46$ to $131 \mathrm{vs}-78$ to $51 \mathrm{~mL}$, respectively; $\mathrm{p}=0.004)$. Median time to liberation after DPS was significantly shorter (10 vs 29 days; $95 \% \mathrm{Cl}$ 6.5 to 13.6 vs 23.1 to 35.3 days; $p<0.001$ ). Adjusted hospital charges were significantly lower for DPS on multivariate linear regression models controlling for year of injury, sex, race, injury severity, and age $(p=0.003)$. Discussion DPS implantation in patients with acute $\mathrm{CSCl}$ produces significant improvements in spontaneous $\mathrm{Vt}$ and reduces time to liberation, which translated into reduced hospital charges on a risk-adjusted, inflationadjusted model. DPS implantation for patients with acute $\mathrm{CSCl}$ should be considered.

Level of evidence Level III.

\section{INTRODUCTION}

Although acute cervical spinal cord injury (CSCI) is uncommon with about 17,000 new injuries each year, it is devastating and costly. ${ }^{1}$ Average costs in the first year following a cervical spinal cord are estimated to be $\$ 1.1$ million for a high cervical spinal cord injury and about $\$ 800,000$ for a low cervical spinal cord injury. ${ }^{1}$ Each subsequent year of care will cost between $\$ 120,000$ and $\$ 196,000$ per year depending on level of CSCI. For a 25 -year-old patient with an acute CSCI, the lifetime cost of care is $\$ 3,660,000$ to $\$ 5,000,000$ depending on injury level.
In an effort to limit costs, authors have looked at various aspects of the comprehensive care in order to identify possible cost savings. Previous works have shown that respiratory complications are a main driver of increased costs. ${ }^{2}$ Furlan and colleagues compared spinal decompression within 24 hours in patients with acute CSCI to those who had decompression beyond 24 hours and found that early decompression saved about $\$ 11,000$. $^{3}$ Gamblin and colleagues looked at the cost of inpatient rehabilitation following acute CSCI and suggested improved efficiency of rehabilitation care could decrease costs of care. ${ }^{4}$

As part of a comprehensive care program for patients with acute CSCI, we have used diaphragm pacing implantation (DPS) in an effort to prevent diaphragm atrophy and facilitate liberation from mechanical ventilation. In a multicenter trial, Posluszny et $a l^{5}$ demonstrated that early DPS implantation following acute CSCI facilitated liberation from mechanical ventilation in an average of 10.2 days. Our previous work showed that DPS was safe and feasible, ${ }^{6}$ and that it would increase spontaneous tidal volume and facilitate liberation form mechanical ventilation (personal communication).

Based on our previous work, we wanted to examine the impact on hospital costs for the acute care hospital stay for patients with acute CSCI. Our hypothesis was that early implantation of DPS would decrease hospital costs.

\section{METHODS}

This was a single-institution, retrospective cohort study from an American College of Surgeonsverified Level I trauma center in the southeastern United States. Our trauma registry and professional billing database were queried to identify patients with spinal cord injuries between January 2005 and May 2017. We performed a continuing review of the data used for our previous work. ${ }^{6}$ This work was reviewed by the University of Florida Institutional Review Board and was determined to be exempt from review. Since it was a review of existing registry data, patient consent for participation was not required.

In July 2011, our institution began using DPS implantation in an effort to facilitate liberation from mechanical ventilation in patients with acute CSCI. Before this time, no patients received pacers, but once we began performing laparoscopic DPS implantation, all patients admitted with acute CSCI were evaluated for DPS implantation. Key predictor variables studied were age, gender, year of injury, 
injury severity score (ISS), level of cervical spinal cord injury, and Glasgow Coma Scale score as a marker for concomitant traumatic brain injury. Outcome measures were ventilator liberation before discharge, days to liberation from ventilator, Vt change before discharge in milliliters $(\mathrm{mL})$, and mortality. Patients with complete respiratory mechanics data were analyzed and compared. Those who did not have DPS (NO DPS) had spontaneous Vt recorded at time of ICU admission, at day 7, and day 14; patients who had laparoscopic DPS implantation (DPS) had spontaneous $\mathrm{Vt}$ recorded before and after DPS implantation. Specifically, we recorded the largest spontaneous Vt within the 72 hours prior to DPS implantation and the 72 hours after DPS implantation. Time to ventilator liberation and changes in size of spontaneous $\mathrm{Vt}$ for patients while on the ventilator were analyzed.

We used propensity scoring based on age, gender, ISS, and emergency department systolic blood pressure to identify a comparison cohort from the earlier patients who, had they presented at a later date, would likely have received DPS implantation. We used mean values for propensity score matching. These confounding variables were chosen to identify the impact of injury burden and presence of shock on emergency department admission on our outcomes. Our primary outcome of interest was adjusted hospital charges. Total hospital charges were included in our trauma registry. This does not include the professional fees for the surgical procedure or for inpatient care. The charge for the DPS device is $\$ 31,000$. The device operates on one lithium battery, which lasts approximately 20 days. Lithium batteries are available commercially from multiple vendors for varying costs as low as $\$ 15$ per battery. These charges were normalized to 2016 data using a publicly available calculator based on the medical consumer price index (https://www. in2013dollars.com/Medical-care/price-inflation). ${ }^{7}$ Bivariate and multivariate linear regression models were calculated to determine the independent effects of diaphragm pacer implantation on adjusted hospital charges, while controlling for age, injury severity, and year of arrival (in the event that intensive care unit (ICU) charges increased annually more than the medical consumer price index). We also created models including hospital length of stay and ICU length of stay, and pneumonia during the hospital stay. All statistics were performed using STATA V.10 (StataCorp 2007, College Station, TX).

\section{RESULTS}

During the study period from January 2005 to July 2017, we identified 649 patients with acute CSCI. All patients were critically injured and required comprehensive care in the intensive care unit. Beginning in July 2011, we added DPS implantation to our comprehensive care of patients with acute CSCI in an effort to facilitate liberation from mechanical ventilation. After this, we identified 40 DPS patients who were propensity matched to 61 CSCI patients who did not have DPS implantation (NO DPS group). The DPS group was slightly older but otherwise the groups were well matched (table 1).

Blunt mechanism predominated in both groups with motor vehicle crash being the most common (table 2).

Level of cervical spine injury was analyzed and classified into high (C1-4) and low (C5-7) with about two-thirds of patients in each group having a low-level injury. More than $80 \%$ of patients in each group were noted to have a complete CSCI (table 3).

Changes in respiratory function were analyzed for both groups. Following DPS implantation, patients had an $88 \mathrm{~mL}$

\begin{tabular}{|c|c|c|c|}
\hline & DPS $(n=40)$ & None $(n=61)$ & $P$ value \\
\hline Age & $45 \pm 16$ & $39 \pm 16$ & 0.05 \\
\hline Race & & & 0.76 \\
\hline Black & $16(40 \%)$ & $20(33 \%)$ & \\
\hline White & $20(50 \%)$ & $34(56 \%)$ & \\
\hline Other & $4(10 \%)$ & $7(11 \%)$ & \\
\hline Sex & & & 0.04 \\
\hline M & $29(73 \%)$ & $54(89 \%)$ & \\
\hline $\mathrm{F}$ & $11(27 \%)$ & $7(11 \%)$ & \\
\hline Insurance & & & 0.17 \\
\hline Unknown & $2(5 \%)$ & $7(11 \%)$ & \\
\hline Commercial & $27(68 \%)$ & $28(46 \%)$ & \\
\hline Medicaid & $5(13 \%)$ & $15(25 \%)$ & \\
\hline Medicare & $5(13 \%)$ & $6(10 \%)$ & \\
\hline None & $1(1 \%)$ & $5(8 \%)$ & \\
\hline ISS & $38 \pm 17$ & $39 \pm 18$ & 0.74 \\
\hline ED SBP & $78 \pm 19$ & $80 \pm 14$ & 0.47 \\
\hline GCS & $13 \pm 2$ & $13 \pm 4$ & 0.31 \\
\hline Level of injury & & & 0.82 \\
\hline $\mathrm{C} 1-\mathrm{C} 4$ & $14(35 \%)$ & $20(33 \%)$ & \\
\hline $\mathrm{C} 5-\mathrm{C7}$ & $26(65 \%)$ & $41(67 \%)$ & \\
\hline Mechanism of injury & & & 0.12 \\
\hline Blunt & 38 (95\%) & $52(85 \%)$ & \\
\hline Penetrating & $2(5 \%)$ & $9(15 \%)$ & \\
\hline Als chest & $3.5 \pm 1.1$ & $3.1 \pm 1.2$ & 0.33 \\
\hline AIs face & $2.3 \pm 1.3$ & $1.8 \pm 0.5$ & 0.32 \\
\hline
\end{tabular}

AIS, Abbreviated Injury Scale score; ED SBP, emergency department systolic blood pressure; GCS, Glasgow Coma Scale score; ISS, injury severity score.

increase in their spontaneous Vt compared with a decrease of 13 $\mathrm{mL}$ in spontaneous $\mathrm{Vt}$ in patients in the NO DPS group (table 4).

This difference was statistically significant $(p=0.008)$. Patients in the DPS group were liberated from mechanical ventilation in a mean of 10.1 days compared with a mean of 29.2 days in the NO DPS group. This difference was statistically significant $(\mathrm{p}<0.001)$.

Given the significant decrease in ventilator days in the DPS group, we then analyzed the total hospital charges normalized to 2016 data for each group. Resource utilization was high in both groups and so were total hospital charges. Average hospital charges for patients (table 5) in the DPS group were $\$ 639,093$ (95\% CI $\$ 524,041$ to $\$ 754,144)$ while the average charges for the NO DPS group were $\$ 784,536$ (95\% CI $\$ 695,615$ to $\$ 874,458)$. This difference in charges was statistically significant $(\mathrm{p}=0.003)$.

\begin{tabular}{lcc}
\hline Table 2 & Mechanism of injury \\
\hline Mechanism & DPS group $(\mathrm{n}=40)$ & NO DPS group $(\mathrm{n}=61)$ \\
\hline Motor vehicle crash & 19 & 23 \\
\hline Motorcycle crash & 2 & 6 \\
\hline ATV crash & 1 & 0 \\
\hline Fall & 12 & 13 \\
\hline Bicycle crash & 2 & 1 \\
\hline GSW & 2 & 9 \\
\hline Pedestrian struck & 0 & 3 \\
\hline Diving & 1 & 3 \\
\hline Others & 1 & 3 \\
\hline
\end{tabular}

ATV, all-terrain vehicle; GSW, gunshot wound. 


\begin{tabular}{lll}
\hline Table 3 & Level of cervical spinal cord injury & \\
\hline Level of injury & DPS group ( $\mathbf{n}=40)$ & NO DPS group $(\mathbf{n}=61)$ \\
\hline High (C1-4) & $35 \%$ & $33 \%$ \\
\hline Low (C5-7) & $65 \%$ & $67 \%$ \\
\hline Complete injury & $35(88 \%)$ & $50(82 \%)^{*}$ \\
Incomplete injury & $5(12 \%)$ & $9(15 \%)^{*}$ \\
\hline
\end{tabular}

*Two patients in the NO DPS group did not have documentation of complete or incomplete injury.

\section{DISCUSSION}

This continues our work on the use of DPS in acute $\mathrm{CSCI}^{5} 6$ and represents the largest single institution experience with DPS implantation for acute CSCI to date. We demonstrate that the early implantation of DPS for patients with acute CSCI will improve spontaneous $\mathrm{Vt}$, decrease time to ventilator liberation, and mostly importantly reduce acute hospital costs. Early DPS implantation improves maximum spontaneous Vt by about 100 $\mathrm{mL}$ and allowed liberation from mechanical ventilation in an average of 10.2 days. The patients in the NO DPS group actually had a decrease in their spontaneous Vt which we hypothesize is from diaphragm atrophy secondary to use of mechanical ventilation for respiratory failure secondary to the CSCI. Facilitating earlier ventilator liberation resulted in a decrease of acute care hospital costs by $\$ 144,443$. We hypothesize this decrease in hospital charges is due to the decrease in the number of ventilator days and a decrease in all of the charges associated with ventilator usage. We had hoped we could reduce the incidence of pneumonia, but our prior work did not demonstrate a reduction. ${ }^{6}$ Given the focus in the USA on decreasing costs and improving value, implementing DPS implantation as part of a comprehensive care program for patients with acute CSCI has important implications for cost reduction in the future. ${ }^{8}$

Acute CSCI is a relatively uncommon but devastating injury that has extensive associated resource utilization and costs of care. ${ }^{19}$ The largest costs tend to be early after injury as first year of cost for a high spinal cord injury (C1-4) is estimated to be about $\$ 1.1$ million and for a low CSCI (C5-7) is estimated to be about $\$ 800,000 .{ }^{1}$ Other authors have also demonstrated that the first year of care following CSCI are the most costly. ${ }^{1011}$ Gamblin and colleagues showed that the costs of the first year of care were high and impacted by the amount of time spent in rehabilitation. ${ }^{4}$ They suggested that efficacy of rehabilitation would help reduce costs. Our study demonstrated costs that were similar, but lower, to other estimates because our costs only include the time spent in acute care. Using DPS to facilitate liberation from mechanical ventilation has the potential to reduce the time spent in acute care and hasten the transition to rehabilitation care. This in turn could improve the efficacy of rehabilitation as Gamblin suggested. ${ }^{4}$

Although this study is the largest single-institution experience for DPS use in acute CSCI, it does have some limitations. It is a single-institution, retrospective review with a small number of patients, so our results could be skewed. Our analysis of charges only includes the total hospital charges and not professional charges for surgery or inpatient care. Future studies could also include professional charges. We reviewed our experience over

Table 4 Risk-adjusted respiratory outcomes in propensity-matched patients with and without diaphragm pacing

\begin{tabular}{lccc}
\hline & DPS $(\mathrm{n}=40)$ & None $(\mathrm{n}=61)$ & P value \\
\hline Vt change before discharge $(\mathrm{mL})$ & $88.2 \pm 21$ & $-13.8 \pm 32$ & 0.008 \\
Days to liberation from ventilator & $10.1 \pm 1.7$ & $29.2 \pm 3$ & $<0.001$ \\
\hline
\end{tabular}

Table 5 Average hospital charges for patients with acute cervical spinal cord injury

\begin{tabular}{llll}
\hline Group & Charges (\$) & SD (\$) & $95 \%$ Cl (\$) \\
\hline NO DPS ( $n=61)$ & 783,537 & 271,228 & 695,615 to 871,459 \\
\hline DPS ( $=39)$ & 639,093 & 449,223 & 524,042 to 754,145 \\
Savings & $144,444^{*}$ & & \\
\hline${ }^{*} p=0.003$. & & &
\end{tabular}

a long period of time (2005-2017), so changes in the delivery of critical care could have factored into the outcomes of these patients. Over the study period, we have implemented changes such as hemostatic resuscitation, decreasing sedation and analgesia, increased focus on early mobility, and use of airway pressure release ventilation that have undoubtedly improved patient care and are difficult to account for in improved patient outcomes. A multicenter trial over a shorter period may help us to answer our questions definitively.

Even though we have some limitations, this study adds important new information to the current literature on the use of DPS in patients with acute CSCI. We have shown that using DPS implantation to facilitate liberation and reducing patient care costs can be an important part of the comprehensive critical care of patients with acute CSCI.

\section{CONCLUSIONS}

Acute CSCI is both devastating and costly. We have shown previously that DPS can be performed safely. ${ }^{5}$ Given the finding of improvements in spontaneous $\mathrm{Vt}$, which facilitates liberation and reduces hospital costs, it makes sense to include DPS implantation as part of comprehensive critical care management of these patients.

Contributors AJK: study design, data collection, data analysis, manuscript preparation. YDZ, JM: data collection. BKY: patient recruitment, data collection, manuscript editing. MLC: data analysis, study design, manuscript editing. ATH, FGM, DJE, DJS, JS: patient recruitment, manuscript editing.

Funding The authors have not declared a specific grant for this research from any funding agency in the public, commercial or not-for-profit sectors.

Competing interests None declared.

Patient consent for publication Not required.

Provenance and peer review Not commissioned; externally peer reviewed.

Data availability statement Data available from corresponding author on reasonable request.

Open access This is an open access article distributed in accordance with the Creative Commons Attribution Non Commercial (CC BY-NC 4.0) license, which permits others to distribute, remix, adapt, build upon this work non-commercially, and license their derivative works on different terms, provided the original work is properly cited, appropriate credit is given, any changes made indicated, and the use is non-commercial. See: http://creativecommons.org/licenses/by-nc/4.0/.

\section{ORCID iDs}

Andrew J Kerwin http://orcid.org/0000-0003-4372-5813

Marie L Crandall http://orcid.org/0000-0002-6536-3123

\section{REFERENCES}

1 Center NSCIS. Spinal cord injury (SCI) facts and figures at a glance. Birmingham, Alabama, 2019.

2 Winslow C, Bode RK, Felton D, Chen D, Meyer PR. Impact of respiratory complications on length of stay and hospital costs in acute cervical spine injury. Chest 2002;121:1548-54.

3 Furlan JC, Craven BC, Massicotte EM, Fehlings MG. Early versus delayed surgical decompression of spinal cord after traumatic cervical spinal cord injury: a cost-utility analysis. World Neurosurg 2016;88:166-74. 
4 Gamblin A, Garry JG, Wilde HW, Reese JC, Sherrod B, Karsy M, Guan J, Mortenson J, Flis $A$, Rosenbluth JP, et al. Cost analysis of inpatient rehabilitation after spinal injury: a retrospective cohort analysis. Cureus 2019;11:e5747.

5 Posluszny JA, Onders R, Kerwin AJ, Weinstein MS, Stein DM, Knight J, Lottenberg L, Cheatham ML, Khansarinia S, Dayal S, et al. Multicenter review of diaphragm pacing in spinal cord injury: successful not only in weaning from ventilators but also in bridging to independent respiration. J Trauma Acute Care Surg 2014;76:303-9.

6 Kerwin AJ, Yorkgitis BK, Ebler DJ, Madbak FG, Hsu AT, Crandall ML. Use of diaphragm pacing in the management of acute cervical spinal cord injury. J Trauma Acute Care Surg 2018;85:928-31.

7 Foundation OD. Medical care inflation calculator, 2019
8 Dieleman JL, Baral R, Birger M, Bui AL, Bulchis A, Chapin A, Hamavid H, Horst C, Johnson EK, Joseph J, et al. US spending on personal health care and public health, 1996-2013. JAMA 2016;316:2627-46.

9 Furlan JC, Gulasingam S, Craven BC. The health economics of the spinal cord injury or disease among veterans of war: a systematic review. J Spinal Cord Med 2017:40:649-64.

10 Chan BC-F, Cadarette SM, Wodchis WP, Krahn MD, Mittmann N. The lifetime cost of spinal cord injury in Ontario, Canada: a population-based study from the perspective of the public health care payer. J Spinal Cord Med 2019;42:184-93.

11 Munce SEP, Wodchis WP, Guilcher SJT, Couris CM, Verrier M, Fung K, Craven BC, Jaglal SB. Direct costs of adult traumatic spinal cord injury in Ontario. Spinal Cord 2013:51:64-9. 